pendence on the beneficial parasitic fungi. The appearance of the fruit on the market would be vastly improved. The total dependence of the Florida ritrus grower on natural enemies for the control of the pests on citrus trees is a delusion.

February 2, 1915.

Presiden' H. T. Fernald: The next paper on the program will be read by P. J. Parrott.

\title{
AN ANALYSIS OF SPRAYING METHODS AGAINST THE CODLING MOTH
}

\author{
By P. J. ParrotT
}

One who has at heart the permanent prosperity, extension and normal development of fruit-growing in New York can hardly fail to be impressed with two facts: (1) The increased planting of apple trees, so that the care of orchards frequently over-shadows all other farm operations, resulting in an unbalanced state of farming; and (2) the growing necessity of more frequent and thorough applications of spraying mixtures. In addition to scab, scale and codling moth, it is now the lot of many orchardists to have to contend against fruitpuncturing capsids and leaf and fruit-infesting aphides; and spraying for these has become a regular part of the routine prescribed by the latest and most approved spraying schedule. The cost for spray materials is also increasing. Formerly lime-sulphur and arsenate of lead sufficed for the principal ills that the apple is heir to, but now the grower must needs use lime-sulphur and lead, plus other substances; and according to present usage nicotine is the most popular third constituent in the combination of spraying materials.

Individually and collectively the growers of New York are confronted with what may prove to be a great economic problem. In addition to the necessity of maintaining a high state of culture at increasing expense, they are apparently facing a period of diminishing returns. As a result more serious thought than ever before is being given to a study of methods of producing maximum yiclds of highgrade fruit at minimum cost. A partial solution of the dilemma is to improve spraying practices, at least as to the character, if not number, of the treatments. In spite of present methods, injurious insects are responsible for great reductions in financial returns. Moreover, in addition to direct losses, failure to maintain a high level of spraying practices may have the effect of neutralizing, if not actually destroying any benefit by other standard operations, as pruning, thinning, cultivation, etc., so essential today for the upkeep and 
profitable production of the orchard. The objection to such a proposition by the average orchardist at first thought is, I fancy, that of cost; it being urged that most growers are already putting more into this operation than can be afforded, and one which, in addition to other objectionable features, calls for a cash outlay. A study of orchards under Station control suggests that the problem is in reality not so much a matter of cost as a matter of time,--to find time to spray the trees thorougbly at each critical period, and yet not neglect other orchard operations or other crops when they too demand proper attention.

As to expensiveness of spraying, the duchter ${ }^{1}$ orchard, now in its fourth decade, has yielded the Station during the past decennium a net profit per year of $\$ 120.60$ per acre. On the cost sheet for a barrel of apples are nine items of expense amounting to $\$ 1.29$, which covers the growing, harvesting and delivery of the fruit to the railroad station. In order of importance as regards extent, spraying ranks as fifth in the list, and amounts to only $7 \frac{1}{2}$ per cent of the whole cost involved in producing a barrel of apples for the market. This sum is not large, and considered in the light of losses sustained, it appears that more money could- well be expended for spraying operations. Inder present conditions this would necessitate more spraying rigs and additional crews of men, with the attendant difficulty of finding profitable employment for both horses and men when their presence was not needed in the orchard. These considerations suggested the wisdom of purchasing and testing out a high-pressure outfit as one possible means of developing economy and raising the efficiency of spraying practices in New York. It was thought that with an outfit of large capacity and power not only could more acres of orchard be sprayed within a given time, but that with a great volume of spray under high pressure, more effective work could be done against such pests as fruit-puncturing capsids, pear thrips, apple aphides and perhaps the codling moth.

Because of unfamiliarity as regards the essentials for such an outfit we sought the advice of Dr. A. L. Melander and, in accordance with his specifications, we purchased a spraying machine which is capable of maintaining a pressure of 300 pounds or more and discharging a flow of spraying mixture as high as fifteen gallons per minute, with a set of four "Clipper" nozzles. The hose was in two lengths of fifty feet, furnished with extra long couplings and equipped with eight-foot brass-corcd extension-rods. The outfit, when carrying a load of two hundred gallons of spray, had a weight of about 3600 to 3800 pounds, which is less than that of some machines we have used in the past.

1 Geneva Bulletin 376, 1914. 
Of the various experimental activities conducted also under the immediate supervision of one cntirely familiar with the western methods of high-pressure spraying, two projects are at this time of special interest: (1) Penetration of spraying mixtures to lower calyx cavity of apples by high and low pressures, using respectively Bordeaux and Vermorel nozzles, and (2) Comparative effectiveness of high and low pressures with the foregoing two types of nozzles against the codling moth.

\section{Penetration of Lower Calyx Cavity}

In the experiments against the codling moth it was obvious at the outset, that notwithstanding what system was being followed, only a very small percentage of the young apples showed penctration to the lower calyx cavity by the liquid. In order to get further data on this point it was decided to stain the spraying mixture, which was accomplished by using ten packages of "Diamond Dye, Crimson" to about ten or fifteen gallons of the liquid. The dye was added during the course of the regular spraying operations, as demanded by the tests in a Baldwin orchard, but as soon as the colored spray was being discharged at the nozzles the operators were urged to take special pains to do thorough work, shooting as it were the spraying mixture into the throat of every blossom. Immediate examinations substantiated previous observations, but in order that closer inspections could be made, whole clusters of apples were removed from the trees and examined in the laboratory under a lens, where the condition of each fruit with respect to the penetration of the liquid was noted. The data, as finally classified, is contained in the following table:

Table I. Showng Penetration by Bordeadx and Vramoret Nozzleg

\begin{tabular}{|c|c|c|c|c|}
\hline \multirow{2}{*}{ Condrtions or Calyx Caytty } & \multicolumn{2}{|c|}{ Termorel Nozzles } & \multicolumn{2}{|c|}{ Bordeaux Nozzles } \\
\hline & No. & Per cent & No. & Per cent \\
\hline 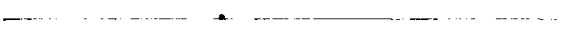 & & & & - \\
\hline Apples examined. $\ldots \ldots \ldots \ldots \ldots \ldots \ldots \ldots \ldots \ldots$ & 135 & & 62 & \\
\hline Apples with spray in lower cavity........... & 0 & & 0 & $\cdot$ \\
\hline Apples stained at point of contact of stamens. . . . . . . . & 9 & 0.6 & 5 & 8.1 \\
\hline Apples with traces of stained pollen in lower csvity....... & 32 & 23.7 & 12 & 19.4 \\
\hline Apples with considerable stained pollen in lower cavity...... & 21 & 15.6 & 13 & 21.0 \\
\hline Apples with no stained pollen in lower cavity .......... & 82 & 60.7 & 37 & 59.7 \\
\hline
\end{tabular}

Comparative Effectiveness of High and Low Presstre Spraying Against the Codling Moth

In view of the foregoing figures it is now of interest to note the results of spraying in this orchard with respect to the protection of the crop by the two methods of spraying. Arsenate of lead was 
used in amounts varying from one to three pounds to fifty gallons of water. The strength of lime-sulphur was one gallon of concentrate testing $32-34^{\circ} \mathrm{B}$. to forty gallons of water. Applications were made with pressures of 300 pounds or more with Bordeaux nozzles and about 200 pounds with Vermorel nozzles.

Table II. Showing Resulta from High and Jow Pagagdre Spraying

\begin{tabular}{|c|c|c|c|c|c|c|c|}
\hline \multirow{3}{*}{ Conditions } & \multirow{2}{*}{ Sound Apples } & \multicolumn{2}{|c|}{ End Wormy } & \multicolumn{2}{|c|}{ Side Wormy } & \multirow{2}{*}{$\begin{array}{l}\text { Total No. } \\
\text { of Apples }\end{array}$} & \multirow{2}{*}{$\begin{array}{l}\text { Per cent } \\
\text { Wormy }\end{array}$} \\
\hline & & No. & Per ecnt & No. & Per cent & & \\
\hline & & & & & $\cdot$ & & \\
\hline Vermorel 3 lthe to $50 .$. & 7603 & 60 & 0.72 & 645 & 7.76 & 8308 & 8.48 \\
\hline Yermurel 3 lhs, to st.. . & 6192 & 45 & 0.67 & 515 & 7.63 & 6752 & 8.30 \\
\hline Bordenux 3 lhes to $50 .$. & 7532 & .22 & 0.28 & 406 & 5.10 & 7960 & 5.38 \\
\hline Bortcaux 3 lhs. to $50, \ldots \ldots$ & 3376 & 6 & 0.17 & 229 & 6.34 & 3611 & 6.51 \\
\hline Bordcaux $1 \mathrm{lh}, \mathrm{to} 50 . \ldots \ldots \ldots$ & $642 \bar{i}$ & 71 & 1.02 & 439 & 6.33 & 6937 & 7.35 \\
\hline Burdealex 1 llh. to $50, \ldots \ldots \ldots$ & 5079 & 40 & 0.73 & 340 & 6.23 & 5459 & 6.96 \\
\hline Vermurel $1 \mathrm{lb}$. to $50, \ldots \ldots \ldots \ldots$ & $5+1 i$ & 53 & 0.89 & 464 & 7.82 & 5934 & 8.71 \\
\hline Vermorel $1 \mathrm{lb}$, to $50 . \ldots \ldots \ldots \ldots$ & 5250 & 111 & 1.92 & 394 & 6.64 & 5781 & 8.56 \\
\hline Bordeaux 2 Itws. to $50 . \ldots \ldots \ldots$ & 7361 & 20 & 0.26 & 330 & 4.28 & 7711 & 4.54 \\
\hline Bordeaux 2 lhw. to $50 \ldots \ldots \ldots$ & 7710 & 53 & 0.66 & 307 & 3.80 & 8070 & 4.46 \\
\hline Fermorel I. S \& Ised 1-50 ... & 5880 & 103 & 1.56 & 601 & 9.13 & 6584 & 10.69 \\
\hline Bord'aux L. S. \& L'ad 1-50.... & 8331 & 123 & 1.34 & 693 & 7.58 & 9147 & 8.92 \\
\hline Check..................... & 5968 & 318 & 4.45 & 866 & 12.11 & 7152 & 10.56 \\
\hline Cherk.............. & 5280 & $23 t$ & 3.56 & 1055 & 16.06 & 6560 & 19.62 \\
\hline
\end{tabular}

The data as presented are based only on preliminary experiments which were conducted during the past season under the efficient direction of a western expert in order to familiarize our entomological staff with the methods of high-pressure spraying; and there is no necessity for anticipating conclusions. However, it is apparent that the results, while of interest to professional workers, have a practical bearing. To follow the advice that "the spray be directed from above and be driven squarely against each blossom" in a typical apple omard in western New York composed of trees that are high and of great expansion, would raise a lot of new problems, involving largely the sumounting of practical difficulties that would not prove easy to conquer; in fact, if the season's experience is a criterion, would stir up more hares than one would care to run down. On the other hand, if penetration of the lower calyx cavity is not really necessary under our conditions, then the needs of the orchardist can be met with a broad sweeping spray. From this standpoint a high-pressure outfit would still possess merits - rapidity of discharge and carrying power of the spray, affording possibilities for economy of time and a wide field for the development of higher standards of spraying than now generally prevail. 
Mr. C. T. Brues: I am very much interested in this paper, for, as you know, somewhat similar work with high-pressure spraying has been done in the West by various entomologists. I must admit I am not quite familiar with the percentages of sound fruit which are generally obtained in the most successful work in the West. If Mr. Parrott can tell us what the percentages are I would like to know.

Mr. P. J. ParrotT: By means of high-pressure spraying they have been able to grow apples in the West that run 95 to 97 per cent free from injury by codling moth. On the other hand, it is reported that by the use of Vermorel nozzles great losses to the crops are sustained. Evidently eastern and western entomologists, as far as control of the codling moth is concerned, are working under different conditions.

Mr. C. T. Brues: Dr. Melander is also of this opinion. I saw him for a few hours after his return from the experiments in New York, and I judged from what he said that the sprays failed to penetrate, at least to the extent that normally occurs in the West. Is it not possible that there is difference in the position of the floral parts?

Mr. P. J. ParrotT: I believe that is the pith of the matter.

Mr. E. P. FrLT: I would like to ask at what time in the development of the blossom was the spraying done-after the stamens were dry or were they still green?

Mr. P. J. PARrott: The petals had clropped and the stamens were - commencing to shrivel.

Mr. E. G. Truvs: How near did you get to the blossoms and did you actually drive the spray in?

Mr. P. J. Parrott: In the case of the apples, which were examined to determine the extent of the penetration of the colored spray, the nozzles were held quite close to the fruit during spraying operations. These showed no penetration, but it should be stated that in the course of the various experiments the spraying mixture was sometimes found in the lower calyx cavity. Certain it is that, under the conditions in which we were working, it was not an easy thing to force the spray through the different structures in the calyx cup of the Baldwin apple.

Mr. A. L. Quajntance: For the last two or threc years the Bureau has been making a comparative study of the calyx cup in eastern and western apples and it shows that the western apple has a much more open arrangement of the stamen bars than the eastern apples, and this explains the situation. The position of the western entomologist and the position of the eastern entomologist are accounted for by the difference in the arrangement of the stamens.

Mr. P. J. ParrotT: In the October number of the American Naturalist there is an article by Mr. W. J. Young which clearly explains 
the variations in apples due to differences in environment. I hope later to add more to this phase of the question.

Mr. W. M. Scotr: There is another question that Mr. Parrott's paper raises and that is the question of pressure. I think that we have been somewhat extreme on that point. The spray pump people have vied with each other to put out machines that would give the highest pressure and deliver a large quantity of material per minute. The result has been, according to my observation, injury to fruit and foliage by an excess of spraying material in the first place, and in the second place (and I think not an unimportant point either) by actual mechanical injury from driving spray under high pressure.

I have been knocking around over the country quite extensively in the last couple of years, looking into just such matters, and I frequently find apple crops injured by arsenate of lead and lime-sulphur solution. Lpon making inquiry I find that most of that injury is found in orehards where high-pressure machines have been used. Professor Quaintance and I, a few years ago, conducted a coöperative experiment in the use of lime-sulphur solution and arsenate of lead in spraying apples under high pressure. I think we had 300, possibly 350 , pounds pressure and on the trees that we sprayed under that pressure, the foliage was badly injured and the fruit badly burnedto the extent perhaps of 50 per cent loss of the crop. Whereas the adjacent trees sprayed with the ordinary outfit, using the mist type of nozzle, did not show the injury-or at least not very much of it.

I think that is a point we ought to bear in mind in recommending applications with high pressure machines.

Mr. E. (r. Titus: In Utah it appears that 125 pounds is sufficient so far as pressure is concerned. The ordinary barrel pump will give sufficient pressure with the ordinary driving spray and will give better results than a 300-pound pressure outfit. It has been done miny times. So far as penetration is concerned, we can penetrate with this, pressure in a very high percentage of cases. In some recent experiments against the fruit-trec leaf roller, in which the question of the codling moth came in, I had no trouble at all, with an ordinary barrel pump in getting less than one-tenth of one per cent calyx wormy; and less than five per cent side worms in the orchard, and I am certain that we did not get a hundred-pounds pressure. On another orchard we used a power pump, but didn't attempt to get over 150 pounds at any time-I do not think it is necessary. The very high pressures not only injure the apples, but they actually blow some blossoms right off the limbs.

Mr. Watkins: Perhaps you would like to know the policy of the University of Illinois. For five years we have been recommending 
pressure at 125 pounds and nothing higher. This past year we have estimated that we had 1800 per cent moth, that is, 18 worms for every unsprayed apple.

In our 1914 pressure experiments similar to Mr. Parrott's, we found that a pressure of 125 pounds controlled the moth more efficiently than 250 pounds. We also found that nozzles which produced a mist spray were preferable to the Bordeaux nozzle.

Hence I believe in using and continuing to use things which we know to be effective in our own orchard. The troublc $I$ find in our experiment station work is that growers are in the habit of taking up with any new hobby that comes along. Because Professor Melander in the State of Washington is successful in controlling the codling moth by using high pressure, it is no sign that we can have equal success with the same methods here. We can probably get good results regardless of the number of poisoned particles which lodge in the calyx cup.

Mr. A. I. Quaintance: I take the liberty to speak again to endorse the remarks made in regard to pump pressure in spraying. A good deal of evidence is accumulating which indicates that very thorough work may be done in the control of the codling moth by a much lower pressure than is currently believed. I would not be surprised that we shall find that from 125 to 150 pounds pressure, with good thorough spraying; will answer, as well as 200 or 250 pounds pressure. Coarse nozzles, of the Bordeaux type, at least under eastern conditions, do not seem to give superior results in the protection of fruit than Vermorel or Eddy Chamber nozzles, and the latter, as is well known, are much more economical of the spray liquid.

Mr. E. N. Cory: Have you had any experience with the airtight sprayers run at 175 pounds pressure on the principle of the atomizer?

Mr. WA'rkins: The airtight sprayers have changed this year so that it is impossible to justify any recommendations. Last year they were run by a two-cycle engine and no agitator; this year they have a four-cycle engine and an agitator. The Univorsity of Illinois spraying specialist is pretty strong for an agitator, and we did not get one there last year for the simple reason that it did not have an agitator. This year, since it is made with an agitator and the four-cycle engine, it is our intention to test it. I know of several machines that were turned back to the company last year.

President H. T. Fernald: The next paper on the program will be given by Mr. Shelford. 